\title{
Exploring the Difference in Pronouncing /ar/ Between Male and Female Students in a University of Northern China and Their Attitude Towards China English Accent
}

\author{
Wang Bo \\ Graduate Student, Department of English and Applied Linguistics, De La Salle University, Manila, The Philippines
}

$\square$ Corresponding Author: Wang Bo, E-mail: kian1024@hotmail.com

\begin{tabular}{|c|c|}
\hline ARTICLE INFORMATION & ABSTRACT \\
\hline Received: 08 September 2021 & As most English teachers discovered in China, the sound /aI/ is frequently pronounced \\
\hline Accepted: 14 October 2021 & like /e/, which can be considered a typical example of China English. However, even \\
\hline Published: 23 October 2021 & speakers are aware of this phenomenon. They tend to still pronounce the sound as /e/ \\
\hline DOI: 10.32996/jweep.2021.3.10.1 & $\begin{array}{l}\text { unconsciously. Gender and ideology differences may be two of the factors causing this } \\
\text { issue. This paper first distinguishes the pronunciation difference between gender by }\end{array}$ \\
\hline KEYWORDS & comparing the /aI/ pronunciation of the participants who are undergraduate students \\
\hline $\begin{array}{l}\text { China English, accent, gender, } \\
\text { language ideology, language } \\
\text { attitude }\end{array}$ & $\begin{array}{l}\text { from a university in northern China. Then it elicits their ideology to China's English } \\
\text { accent by conducting a semi-structured interview. The results show that there is no } \\
\text { significant difference between male and female participants in the pronunciation of } \\
\text { /ar/, and almost half of the participants think there's no problem to have a China } \\
\text { accent, but only two of them show an awareness of World Englishes. Finally, reasons } \\
\text { and implications are discussed and necessary suggestions are provided. }\end{array}$ \\
\hline
\end{tabular}

\section{Introduction}

\subsection{Background}

The spread of English around the world has brought out a number of varied Englishes which were categorized into three circles by Kachru (1985): the inner circle (native English), the outer circle (English as a second language), and the expanding circle (English as a foreign language). Early studies on World Englishes generally concentrated on the inner circle or out circle. Few scholars would pay attention to the expanding circle because the Englishes used by this group were usually not considered as the members of World Englishes due to people's ideology towards them. However, the ideology evolves as English develops in the expanding circle. This is what's happening in many countries especially in Africa, South Asia, Southeast Asian, East Asia, such as Japan, Korea as well as China.

World Englishes has always been the footing stone for many current studies into the legitimate of different varieties of English, from out circle to expanding circle. The terms like "New Englishes" or "Post-colonial" English emerged long before (Platt, Weber \& Ho, 1984; Kachru, 1985). As a result of the high spread of English, the language has been used as the communicative medium not only between a native English speaker and a non-native English speaker but also between non-native speakers from varied cultural communities as a lingua Franca. Therefore, concepts such as linguistic standards or norms have also been reconceptualized (Jenkins, 2007).

In order to explain the concept of China English, this paper assumes the existence of two possible factors (gender $\&$ ideology) that may predict the performance of Chinese English speakers and addresses two research questions: 1. does gender predict the tertiary students' performance in pronouncing /ai/? 2. what are the tertiary students' attitudes towards China-accented English, as well as other varieties of Englishes?

\section{Literature Review}

Copyright: (c) 2021 the Author(s). This article is an open access article distributed under the terms and conditions of the Creative Commons Attribution (CC-BY) 4.0 license (https://creativecommons.org/licenses/by/4.0/). Published by Al-Kindi Centre for Research and Development, London, United Kingdom. 


\subsection{Englishes Study around the World}

Even though Asian countries are distant from the English as native language communities geographically, English is widely used in those countries due to historical reasons in the past and the reason of globalization in modern times. Englishes in Asia is gradually developing into their own languages in many communities like the Philippines, India, Malaysia, etc. To research the legitimacy of Asian Englishes, standard English ideology was problematized by Tomokazu (2016), and English as a Lingua Franca (ELF) was examined together with the world Englishes paradigm. World Englishes paradigm concerns the legitimacy of localized Englishes, while ELF focuses more on English as a medium of communicating between communities or geographical boundaries. He drew a conclusion that Asian Englishes may be appreciated in terms of both ELF and World Englishes paradigms, but ELF theory can be the only way to conceptualize the legitimacy of Asian Englishes. From another perspective, the world Englishes paradigm draws people's attention to the particular usage of English variants, while ELF highlights more about people's awareness or ideology of using English in international or inter-community interactions. In fact, the two concepts are the two major branches of investigating Englishes variants.

Paradigm can be researched in terms of all linguistic levels such as phonetics, phonology, lexis, syntax, semantics, as well as pragmatics. For instance, to find the sound feature, Daniel and Ee-Ling (2021) conducted a study of monophthong vowels' quality and duration among Japanese English speakers. In addition, rhythmic patterning was another target in their research. The findings reveal these two distinctive features in Japanese English, suggesting the necessity of a 'pluricentric' paradigm. Based on a corpus of ninety-one million words from Legislative Council proceedings (1858-2012), Steven (2015) looked into the evolution of the Hong Kong English lexicon using the Dynamic Model by Schneider. Lexis variant was also an important focus by Zakia Ali-Chand (2021) when he introduced the development of Fuji English. African Englishes are representative varieties in the modern English landscape, consisting of West African English, East African English, and South African English. A number of studies were also conducted to look into the Englishes of this group (e.g., Xu, 2017).

As a major branch of World Englishes, ELF has been frequently studied by many researchers in different communities. Language attitude or ideology can be considered the most popular field that intrigues both academic writers and readers (e.g. Pedro $\&$ Alejandro, 2020; Sean \& John, 2018; Pedro \& Alejandro, 2020; Yusop \& Eric, 2020; Jim, 2019; Edwards, 2015; lan \& Duongthi, 2014). Pedro and Alejandro $(2020 ; 2018)$ contributed two studies on attitude towards South African English. One is the attitude towards standard South African English and black accented English among the black South African indigenous college students. The other also studied attitude, but this time towards the white accents in South Africa. Both studies made use of the Implicit Association Test (IAT) in order to elicit the respondents' subconscious ideology, and in the meantime, revealed the implicit ideology of the new generation to different English variants in South Africa. Sean \& John (2018) also studied participants' attitudes towards South African English and its three other subvarieties but in the United States Scenarios. Yusop \& Eric (2020) put a spotlight on Thai English major university students' attitude towards the ownership of English in Southern Thailand, and findings show it is believed that each individual is entitled to claim the ownership of English as long as it is an English user. This study also indicates that the native background of teachers is irrelevant to their effectiveness of teaching. Jim (2019) and Edwards (2015) study local residents' language ideology in Hong Kong, and they have similar findings that although some participants admit mutual understanding as an important element in communication, most of them seem to consider the native English variant as the standard criteria. lan and Duongthi (2014) look at language attitude from a very different perspective, compared to most other studies on this field: students' perception of native and non-native English teachers in Vietnam and Japan. The respondents are college undergraduate students in Vietnam and Japan, and there are common findings that students assume native English speaker teachers as the model of correct English use, pronunciation as well as the resource of cultural knowledge, while it is believed non-native English teachers are good at teaching grammar and have the advantages of effectively interacting with students due their shared culture and cognition. Some participants hold the view that students should learn from both groups of English teachers depending on the students' language proficiency and which skill is being taught. Those findings indicate the very traditional attitude towards English teaching and learning, treating English as others' and overlooking their own identity as independent English users. This is quite different from other communities which are in Kachru's outer circle.

Another English variety in the outer circle also drew much attention from researchers: Philippine English (PE). As a representative variety of World Englishes, it is also controversial for its speakers to figure out whether PE should be set as the target of English teaching in the country. Isabel (2014) admitted that teaching PE in the country enjoys a series of benefits, such as diminishing the feelings of lacking self-confidence, low self-esteem, as well as intimidation among both teachers and students in the country, which, without any doubt, can bring the learners promising learning outcomes. However, she holds the opinion that PE should not be the norm of teaching English in the Philippines. The first reason lies in the absence of codification of PE and the lack of instructional materials. Secondly, while PE had been frequently concentrated by researchers, actions taken to practice were really rare. Thirdly, PE has always been referred to as educated PE, meaning it's always spoken by elites; hence, other Filipinos' identity has to be marked by their mother tongue instead of a variety of languages associated with its colonial history. Another reason comes from the problems faced by teaching, such as financial shortage, curriculum reform, teacher training, etc. What was 
suggested by Isabel is not teaching any variety of English, whether standard or not, but teaching anything that is based on its "use", highlighting the pragmatic purpose of language using and teaching. A recent study on PE, however, drew a different conclusion. Hjalmar (2020) conducted research looking into the Filipino graduate students' attitudes towards educated PE teaching. The result reveals that the graduate students, including the students in both doctorate and master programs, show their confidence in not only teaching educated PE but also in teaching educated PE together with Standard American English (SAE). The result implies that the graduate students hold the idea, whether on purpose or unconscious, that when educated PE is taught to the Filipino students, it's also necessary to teach SAE to them. This reflects their ambivalent psychology between identity and power. On the one hand, PE as the indigenized variety of English should be spoken by local communities; on the other, SAE as a popular and powerful variety of English is also necessary to be learned. Finally, Hjalmar points out that it is the stakeholders' or policy makers' responsibility to plan the language teaching and learning. The Philippine English researches tell that World Englishes is really an intriguing topic and the ELT issue has always been controversial among researchers and teaching practitioners.

With the development of language psychology in the world, many researchers in China have also concentrated on people's ideologies of a certain language or a particular dialect. China English emerged as one of the key issues.

\subsection{What is China English?}

Since a number of English teaching and learning practitioners do not even hear about China English, it is necessary to clarify what $\mathrm{CE}$ is. It was defined as "a developing variety of English, which is subject to ongoing codification and normalization processes" by $\mathrm{Xu}(2008, \mathrm{p4})$. It is on the basis of British and American English and features the transfer of Chinese linguistic and cultural elements at all levels which can be used in practical intra-cultural and intercultural communication. This is different from the concept of "Chinglish". Many researchers try to distinguish CE from Chinglish. Li (1993) claims that CE comes from normative English but with Chinese features in different linguistics levels such as lexis, syntax, and discourse, while Chinglish is characterized by the interference of L1 and shows unreasonableness to some extent. Fang (2017) argues that it is not an easy task to tell CE from Chinglish sometimes. From the author's point of view, intelligibility plays a pivotal role in determining plausibility. As long as the utterance can be understood by people from another cultural background, it can be considered a variety from China context.

\subsection{Attitude towards China English}

Despite diverse research fields concerning $C E$ as a member of WE, most researchers are more likely to engage in the study of Chinese style English pronunciation as well as the learners' attitudes towards the concept of WE. Huang (2020) conducts a quantitative study to investigate the Chinese English learners' identity which is reflected in their attitudes to English accents. The result shows an ambivalence among the participants who have an evident bias to native accent but at the same time experience a sense of learner identity and linguistic right. Kung \& Wang (2019) conduct a qualitative study of 34 students from an international university in China to explore EFL learners' accent preferences in the attempt of effective EFL communications. It is found that sociocultural and sociohistorical elements have an absolute impact on the learners' accent preference depending on their EFL educational experiences. However, there are other variables that may direct those Chinese EFL learners' accent preference and their own performance such as gender and major. As early as 2016, Fan Fang has investigated the undergraduate students' attitude to English accents in his university in Southeast China. He distributed a questionnaire which was followed by face-to-face interviews. The result shows the reality that most students are still viewing native English accent as their learning objective, although some expressed their resistance to standard English.

Historically, four research strands are identified by Wang (2017): Chinese pidgin English, the pursuit of "correctness" of English, Chinese variety of English, and legitimacy of Chinese speakers' own English, among which the second strand still might be dominant not only in the research field but also among ordinary English practitioners in China. This seems like an implicit agreement between language teachers and students. For instance, traditional studies of English assessment may set standard English in terms of pronunciation, lexis, or grammar as the criteria for evaluating the performance of testees. The Diagnostic College English Speaking Test (DCEST) is taken as a valid model to test the Chinese students' speaking ability (Zhao, 2013). It consists of three sections: reading aloud (testing pronunciation and intonation), individual presentation (testing grammatical accuracy, grammatical complexity, lexicon accuracy, lexicon range, and fluency), and role-play (testing communicative strategy, coherence, and discourse size). The inclusion of pronunciation, intonation, grammar reflects the reality that there are still implicit negative attitudes towards China English without assuming it as a legitimate member of world Englishes. As a matter of fact, there are very rare English education practitioners who have the awareness of world Englishes and categorize China English into illegal usage of English rather than legitimate variants in the world English family. As a result, scholars (e.g. Fan, 2018) attempt to design materials and relevant courses that call for the student's awareness of English as a lingua Franca. Fan is one of the leading researchers who designed and carried out a new class named "Introduction to English as a World Language" as a selective course in a university in China to introduce the spread and localization of English, people's various attitudes or ideologies towards WE and ELT. It is found that there is an attitudinal change among the participants before and after taking the course. They tend to have more confidence in their own accent as a common variety of English as lingua Franca instead of feeling embarrassed or even ashamed of their own accent. The findings also shed light on the future ELT, pedagogy, and curriculum design. 


\subsection{Changing People's Ideology}

It is commonly admitted by most linguists that any users of English do have the right to creatively use English under their particular cultural background, and it is also plausible to have all kinds of Englishes co-exist together. However, almost all the English teachers at the front line are still holding the traditional view, especially in the expanding circle countries, causing the overall ignorance of WE concept. Then linguists tend to shift their research focus from people's ideology to how to change their ideology. The first method that comes to researchers' minds is intervention (Hamid, Hoang \& Nguyen, 2021). They intervened in the participants' learning process by assigning reading materials to Kachru (1992), Jenkins (2006), and Hamid and Baldauf (2013), who conducted questionnaires before and after the intervention. The participants are $80 \%$ China mainland postgraduate students, and most others are also from Asia, including Vietnam, India, Indonesia, Saudi Arabia, South Korea, and Singapore. The result definitely shows a positive impact on the participants' ideology shift to different variants of Englishes.

In the mainland China context, some researches have been conducted for the nativization of English as China English. Liu (2020) proposed this question by focusing on a syntactical language feature - 'modifying-modified' sequence. This is based on a corpus in which more than 1,685 sentences of this syntactical feature are identified, but it is still not widely accepted by the public as an appropriate feature of this English variant. Then the conclusion is drawn that English is still far from nativization in mainland China.

Since a lot of studies were designed to find out the paradigmatic features, particularly in accent, or the public attitudes towards those features, few types of research concentrate on the factors that determine the learners' attitude and their actual performance. As most English teachers discovered in China, the sound /aI/ is frequently pronounced like /e/, which can be identified as a typical example of China English. However, studies on whether this pronunciation is related to gender are rare. This paper assumes that gender is the one variable that affects students' attitude and performance in English pronunciation, and tries to testify these hypotheses.

\section{Methodology}

\subsection{Participants}

This study enrolls forty non-English major undergraduates as the participants. All of the participants are freshmen, undergraduate students, in a university in northern China, and they come from northern China as well. This is distinctive from the context of Fan Fang's study (2016), most of whom participants might come from southern China. As is known, the dialects in southern China are quite different from northern per se. Among the participants, twenty of them are male, and the other half are female. However, when it comes to statistic analysis, there are five outliers for female participants who got extremely different scores from the mass, then they are excluded in the final statistic analysis. Meanwhile, to make the equal number between gender, fifteen male and fifteen female participants are retained ultimately in this study.

\subsection{Procedure}

This study adopts loud reading tests and semi-structured interviews as the instruments. First, two paragraphs of reading materials (see Appendix One) are assigned to the participants one by one, and each participant is required to read the two paragraphs loudly. Then the author did audio-recording for each individual reading. After the reading test, each one is asked two questions (see Appendix Two) to elicit their inner ideologies to the research topic of this study. With all the tests and recordings finished, transcribing work is implemented by the author and his colleague. On one hand, the pronunciation of each reading is analyzed to find out the number of deviations when pronouncing the sound /aI/. This number is counted as the score the particular participant gets from the test. Thus the higher the score one gets, the heavier one has the Chinese accent when pronouncing this sound. On the other hand, the recordings are also transcribed, translated into English, categorized, and analyzed in order to answer Research Question Two.

The instruments used in this study include a tape recorder, two English paragraphs as the reading material, and SPSS software. The reason why /aI/ sound is chosen as a tool to reflect their degree of standard pronunciation is that there is a similar sound in Mandarin which is frequently pronounced as /e/ especially in northern China. Even though students are taught the British or American way of pronunciation, they tend to be influenced by their mother tongue unconsciously. Reading a narrative story would help relax the participants and have them produce the sounds in a natural circumstance. If they read a single sentence or tongue twisters, much attention will be paid to every individual word, leading to an invalid test for this study.

\subsection{Method of Analysis}

For each participant, every pronunciation concerning /aI/ that are deviated from standard norms (British or American pronunciation) is counted. In total, nineteen /aI/ sounds are identified in the two paragraphs, excluding the very common words like "I" because the highly frequent emerge of a particular work would have a sharp impact on the final statistical result. The number of the deviated sounds is added up to get a score for each participant. Then a T-test is conducted between gender groups to 
answer the RQ One. The transcribed interview data are analyzed qualitatively and are categorized into themes to obtain the participants' possible attitudes.

\section{Findings}

\subsection{Gender Difference}

There are 15 male participants and 15 female participants finally in this study. We use the number "1" to represent males and the number " 2 " to represent females. Table 1 shows the means of each group and the standard deviation.

Table 1. Groups Statistics

\begin{tabular}{llllll}
\hline & gender & $N$ & Mean & Std. Deviation & Std. Error Mean \\
\hline score & 1 & 15 & 12.0000 & 4.65986 & 1.20317 \\
\cline { 2 - 6 } & 2 & 15 & 12.4000 & 3.81351 & .98464 \\
\hline
\end{tabular}

The male group gets a mean score of 12.0 , and the female group gets a mean score of 12.4, which are slightly different from each other. The standard deviation of male groups reaches 4.66, a little more than that of the female group 3.81, meaning that the male group participants have a wide score distribution. Whether the scores the two groups obtained are significantly different from each other can be found in the following table.

After conducting the independent T-test analysis, it is shown that the F value is 0.90 , and the $p$-value is 0.35 , much higher than the critical point 0.01 , meaning that there is no significant difference between the two gender groups in terms of their /aI/ pronunciation.

\subsection{Participants' Ideology}

Two questions are asked to the participants to elicit their opinions and attitudes. The first question: when you are talking with a foreigner in English, would you require yourself to speak standard English or would you allow yourself to have a Chinese accent? This is a choice question, but the respondents are also asked to give possible reasons for why they make that choice. Among the 30 respondents, 19 of them chose the former one, and the rest chose the latter, i.e., there are 19 students who consider standard pronunciation as very necessary. Some think standard pronunciation would help them understand the interlocutors and simultaneously be understood.

\section{Respondent 1:}

When facing a foreigner, only when you are speaking standard English, can you make sure what you are talking about can be understood?

This is a common philosophy held by many students. They also think the misunderstanding is an important issue that should be taken into consideration. Those students who hold this point of view often have the experience of not being able to understand spoken English to some extent. Hence, they are anxious about listening to someone speaking English. Actually, the spoken utterances with a heavy accent can be understood without great effort as long as one is familiar with that particular language. Listeners are usually able to comprehend various dialects of their first language because that is their mother language. For instance, a native English speaker has no difficulty in understanding a speaker from India, Africa, or elsewhere, but it is comparatively tougher for a Chinese English learner who is not in very high English proficiency. However, as a native Chinese, one can easily understand many Chinese dialects even though they are not able to speak them. Consequently, comprehensibility would not be a problem when reaching a certain language level.

There are other reasons for choosing to speak standard English. Those students are considering their faces when facing a foreigner.

\section{Respondent 2:}

I think English is becoming more and more internationalized. When I step out of our border one day in the future, the standard spoken English would bring me glory, and more importantly, we can't lose face for our country.

\section{Respondent 3:}


Standard spoken English reflects our professionalism. We, as Chinese, are capable of reaching a high level. Of course, I don't think I would have that chance.

These respondents have the awareness of their own identity and are strongly willing to maintain their reputation. What can also be drawn from these answers is that they subconsciously acknowledge the power of standard English. Although they may lack the confidence of reaching some achievement, this ideology would drive them to move towards this target. There are varied reasons for those who chose the latter option in the first question.

\section{Respondent 5:}

We learn a language for communication. As long as we can understand each other, that's enough. It's not necessary to pursue a standard language.

\section{Respondent 6:}

It's already amazing enough if I can communicate with a foreigner in English. (I don't care how I manage to do so).

Respondents 5 and 6 emphasize the instrumentality of English as a medium but do not pay much attention to the medium itself. Respondent 6 shows its lack of confidence again as an English learner. It is caused by their few chances of practicing.

\section{Respondent 7:}

I don't think there is a problem if I have a Chinese accent. English, as a widespread language, is spoken by people all over the world. Speakers in every corner, more or less, have their local accent. It resembles the various dialects of Chinese in mainland China. The most population has never experienced traveling overseas, lacking a particular language environment. Thus I think it's not a problem.

Respondent 7 has very deep thinking about the varieties of English spoken by people from all regions. It expresses his idea, whether he realized it or not, that when English as a lingua Franca used in a particular region, it has been integrated into the indigenous culture, and English has inevitably been nativized as one of the variants. Another respondent also delivered a similar idea in the interview.

The second question asked to the respondents is when you are learning English, whether you would set British English, American English, or other English as your target? This is to learn about their attitudes to different English variants. The result follows most of the studies in other expanding circle countries. Fourteen of them chose British English, thirteen chose American English, and three chose others. The three who chose others do not prefer any variant of English. They say they would prefer whichever variant is easy for them. Some of them who chose either British English or American English think they feel comfortable when listening to that English. One considers American English to be more casual and more widely used, while another says British English sounds formal and gentle. Those are people's individual preferences. One reason, which accounts for most proportion of the answers, is that "we were taught British English from the beginning when we were in the primary school, so I have been accustomed to British English". This is resulting from the national language education policy.

\section{Discussions}

\subsection{Gender Difference}

It has been corroborated by many scholars that in learning a certain language, female students outperform male students (Gardner and Lambert, 1972; Spolsky, 1989; and Murphy, 2010). The possible reason can be the gender-specific ideology (Danuta, 2014). Girls are always considered to have the tendency of learning a new language better than boys, while boys are considered to learn maths better than girls. Regardless of the degree of truth for this ideology, when girls and boys believe it, it is likely to be realized. However, in the qualitative studies, it is found that teachers and students tend to deny the hypotheses that there is achievement difference between genders in EFL or ESL learning. That is perhaps caused by the lack of convincing evidence for justification of this ideology. In fact, there is a prevailing opinion that it's suitable for girls to major in a language and be engaged in a career related to languages such as language teacher or interpreter. This does exist widely among Chinese teachers or parents who have the power to affect the students in a subconscious way. That's why, generally, the number of female English majors is times larger than that of male English majors in China. Similarly, the number of female teachers is times larger than that of male teachers no matter what the subject is. This could be the reason why girls seem to be more capable of learning a language - they are guided by authorities, like parents or teachers. However, is gender also a variable that is determining EFL learners' English accent?

There are many possible independent variables like learners' mother tongue, teachers' pronunciation, teachers' attitude in teaching sound, etc. No salient evidence has been found to support the hypotheses that girls outperform boys in learning sound. With the help of checking the participants' pronunciation of /aI/, the first research question reveals the relationship between gender and their pronunciation performance. The result shows that there is no significant accent difference between male respondents and female respondents. Here is the possible explanation. Although the gender issue highlights that gender, as one of the variables, 
can influence students' attitude towards learning English, it does not direct students' attitude towards pronunciation. As a result, gender does not play an important role in determining their choice of accent. From another perspective, sound learning capability does not necessarily lead to standard pronunciation or China-accented pronunciation. Attitude plays a part in that, so after investigating the effectiveness of gender on their spoken sound using statistic analysis, the author also conducted a semistructured interview to elicit their attitude towards standard English and China-accented English.

\subsection{Attitude Analysis}

The research field of ideology to English and learners' identity awareness has been increasingly concentrated by many scholars (Fan, 2017; Jinghui, 2018; Ying, 2019). They investigated language ideology and identity in their studies in terms of English teaching at the tertiary level, teaching materials, and primary education. Either in the primary period or at the tertiary level, they all found that the standard English ideology is dominant. The interviews of this study also show similar results. In answering interview Question One, nineteen respondents choose to pursue standard pronunciation when talking with a foreigner. The reasons for this choice can be categorized into three themes: comprehensibility, politeness, and face issue. The first group is concerned about whether they can understand each other if they don't pronounce either British or American English. Listening competence has always been a tough language skill among the four for most Chinese students, including listening, speaking, reading, and writing. They are able to create opportunities for themselves to practice reading or writing, but chances are rare for speaking and listening. The lack of chances undermines many students' confidence, making them unwilling to communicate, either speaking or listening. Teachers' positive response to this group will help extricate from this embarrassment, including the ignorance of standard pronunciation. The second group considers speaking standard English with respect to the listeners. This ideology is the consequence of the current language education policy. Students never experienced the diversity of Englishes, and thus have no awareness of the plausibility of other Englishes. The third group is anxious about losing face for the deviation from standard English. They have a strong sense of identity as Chinese; however, resembling the previous two groups, standard English is considered prestigious and more powerful. They all overlook the idea that as long as one speaks a language, he or she owns the language. Is this idea the reason for the other half of participants to choose the latter option: no problem for speaking China accent? Nine out of eleven who make this choice hold the view that "I don't care about which variety of English I am speaking as long as we can understand each other". What can be inferred from this utterance is that they are not aware of world Englishes either. Only two delivered the idea that it is reasonable to have a variety of Englishes in this world. There are countless cultural differences between borders, so you can never expect a uniform variety from this world with such a rich number of communities. Actually, English has already become lingual Franca in the mind of the two respondents.

The second interview question reveals respondents' attitudes to the wide varieties of English. Fourteen of them choose British English, and thirteen American English as their standard English. Apart from their personal preference, most of them explain that they have been taught British English from the very beginning, or they have been provided American accent listening materials so frequently. Besides, no respondents show preference to any other variety of English. Most possibly it's not because they do not prefer them, but they never heard other varieties. The English landscape in China can be attributed to the language education guide made by the Ministry of National Education. Students in all grades have no chance of exposure to other Englishes, and everyone presupposes that only British English, or American English, is "native English". This leads to the formation of the current language ideology.

\subsection{Implications}

Although a lot of studies include gender as one of the factors that can predict students' linguistic performance and their results generally prove this hypothesis, gender, in this study, is concluded not an independent variable causing learners' pronunciation difference. It is the authorities' ideology, including parents, teachers, etc., that guides young learners' attitude and behavior, thus further resulting in the public's impression that gender plays a role in determining learners' improving their language competence. Ideology is powerful in driving any individual to learn a language. This is also an issue that was investigated again and again in recent researches. The aim of those researches is to shed light on the current language education. Some scholars have begun to try a reformation in teaching English (e.g. Fan, 2017). A Fan designed a new course at the tertiary level, trying to raise awareness and convert students' attitudes towards other varieties of English. However, this is an attempt of reforming from upper-level education. Essential measures should be taken from primary education with the help of stakeholders' policy-making, material compiling, and teacher education so that the traditional ideology can be shifted in essence. In the assessment of students' language competence, sound, intonation, and grammar mistakes can be attached to less importance. Instead, more proportion of score should be allocated to vocabulary accuracy and range, grammar diversity, communicative competence, and literacy ability. Apart from doing so, students should also be encouraged to practice not only in classrooms but also outside classrooms.

As a matter of fact, an ideal reform of language teaching should transfer learners' center of learning from language itself, including sound, intonation, grammar, and syntax, to its pragmatic and cultural functions. This argument is in accordance with Isabel's (2014) in terms of emphasizing the "use" of language. This approach would not only promote the learners' practical achievements but also drive the learners to improve by themselves. For example, a vocational college in China asked each of its e-commerce majors to run a real international online shop, grading whom on the basis of the amount of money they were able to earn. The result 
shows that students were much inspired by this grading method and sought every opportunity to improve their English proficiency in order to be graded more. In future language education, the awareness of standard English should be undermined; instead, the "use" of English should be more frequently focused on. This is supposed to be planned and implemented by policymakers at the nationwide level.

\section{Conclusion}

This study first tests the role of gender in predicting Chinese EFL learners' accents, arguing that gender is not a direct variable that causes learners' differences in pronunciation performance as well as in other linguistic levels. The determining factor should be the ideology that students' had formed from the very beginning when they learned the language. Twenty-eight out of thirty respondents show their unawareness of World Englishes in this study, proving the importance of developing a positive and inclusive attitude to all varieties of English again. Most of them also assume British English or American English as the only standard English, overlooking the phenomenon of nativization of English as a lingua Franca. Finally, it is suggested that the stakeholders should take action to change the current linguistic education landscape by making new policies, compiling new English learning materials, and implementing new teacher training plans in the entire education system.

Funding: This research received no external funding.

Conflicts of Interest: The author declares no conflict of interest.

\section{References}

[1] Daniel D. L. \& Ee-Ling L. (2021) The sounds of Japanese English: Monophthong vowels and rhythmic patterning. Asian Englishes, 23(1), 3050.

[2] Danuta G. (2014). The impact of gender on attainment in learning English as a foreign language. Studies in Second Language Learning and Teaching, 4 (4), 2014. 617-635.

[3] Edwards J.G. H. (2015). Hong Kong English: attitudes, identity, and use. Asian Englishes, 17(3), 184-208,

[4] Fan F. \& Will B. (2017). 'A more inclusive mind towards the world': English language teaching and study abroad in China from intercultural citizenship and English as a lingua Franca perspectives. Language Teaching Research, 22(5), 608-624.

[5] Fan F. (2016). Investigating attitudes towards English accents from an ELF framework. The Asian Journal of Applied Linguistics, 3(1), 68-80.

[6] Fan F. (2018). Ideology and identity debate of English in China: past, present, and future. Asian Englishes, 20(1), 15-26.

[7] Fan F. (2017). World Englishes or English as a Lingua Franca: Where does English in China stand? English Today, 33(1), $19-24$.

[8] Fan-W., \& Xue w. (2019). Exploring EFL Learners' Accent Preferences for Effective ELF Communication. RELC Journal, 50(3), $394-407$.

[9] Gardner, R. C., \& Lambert, W. (1972). Attitudes and motivation in second language learning. Rowley, MA: Newbury House.

[10] Hamid M. O, Ngoc T \& Trang T (2021). Changing teacher learners' language ideologies and pedagogical practices: an action research intervention in World Englishes. Asian Englishes, DOI: 10.1080/13488678.2021.1914898.

[11] Hamid, M. O., \& Baldauf, R. B., Jr. (2013). Second language errors and features of world Englishes. World Englishes, 32(4), $476-494$.

[12] Hjalmar P. H,. (2020). Filipino Graduate Students' Attitudes Toward Teaching Educated Philippine English: A Sample From a Premier Teacher Education Institution. Asia-Pacific Social Science Review, 20(1), 31-42.

[13] Ian W., \& Duongthi H. O. (2014). Native and Non-Native English Language Teachers: Student Perceptions in Vietnam and Japan. SAGE Open, April•June, 1-9, DOI: 10.1177/2158244014534451.

[14] Isabel P. M. (2014). English language teaching in the Philippines. World Englishes, 33(4), 472-485.

[15] Jenkins, J. (2006). Points of view and blind spots: ELF and SLA. International Journal of Applied Linguistics, 16(2), 137-162.

[16] Jenkins, J. (2007). English as a Lingua Franca: Attitude and Identity. Oxford: Oxford University Press.

[17] Jim Y. (2019). The choice of English pronunciation goals: different views, experiences, and concerns of students, teachers and professionals, Asian Englishes, 21(3), 264-284.

[18] Jinghui S (2019). English as a native language, World Englishes and English as a lingua Franca-informed materials: acceptance, perceptions, and attitudes of Chinese English learners. Asian Englishes, 21(2), 190-206.

[19] Kachru, B. B. (1992). World Englishes: Approaches, issues, and resources. Language Teaching, 25 (1), 1-14.

[20] Kachru, B. B. (1985).'Standards, codification and sociolinguistic realism: The English language in the outer circle.' In: R. Quirk \& H. G. Widdowson (eds.), English in the World: Teaching and Learning the Language and Literatures. Cambridge: Cambridge University Press, 11-30.

[21] Kaiwen L (2020). Is China English Transforming into Nativization Stage? A Case Study of 'modifying-modified' Sequencing in China English. Journal of World Englishes and Educational Practices (JWEEP), 2(4), 44-49.

[22] Li, W. (1993). China English and Chinglish. Foreign Language Teaching and Research, 4, 18-24.

[23] Murphy, B. (2010). Foreign language learning in Irish second-level schools: Gender very much on the agenda. Irish Educational Studies, 29, 81-95.

[24] Pedro Á. \& Alejandro M. (2018). Implicit Language Attitudes Toward Historically White Accents in the South African Context. Journal of Language and Social Psychology, 37(2), 238-248.

[25] Pedro Á \& Alejandro M (2020). Language Attitudes in a Lingua Franca: The Case of Black South African College Students. Journal of Language and Social Psychology, 40(3), 378-397.

[26] Platt, J. T., Weber, H. \& Ho, M. L. (1984). The New Englishes. London, Melbourne: Routledge \& Kegan Paul.

[27] Sean K., \& John W (2018). Worlds Apart: A Study of Attitudes Toward Varieties of South African English Accents in a United States Employment Scenario. Journal of Language and Social Psychology, 37(6), 692-705. 
[28] Spolsky, B. (1989). Conditions for second language learning. Oxford: Oxford University Press.

[29] Stephen E. (2015). Testing the Dynamic Model: The Evolution of the Hong Kong English Lexicon (1858-2012). Journal of English Linguistics, $43(3), 175-200$.

[30] Tomokazu I. (2016) World Englishes and English as a Lingua Franca: conceptualizing the legitimacy of Asian people's English. Asian Englishes, 18(2), 129-140.

[31] Wang, Y. (2017). Chinese English as a lingua Franca: an ideological inquiry. In J. Jenkins, W. Baker, and M. Dewey. (eds.) The Routledge Handbook of English as a Lingua Franca. Routledge.151-164.

[32] Wenpu W \& Lin W. (2016). Chinese English in as lingua Franca in a global business setting: A case study of ongoing emails of a foreign company in China. SHS Web of Conferences 25, DOI: 10.105013.

[33] Xiaohui X. (2017). Corpus-based Study on African English Varieties. Journal of Language Teaching and Research, 8(3), 615-623.

[34] Xu, Z. (2008). Analysis of syntactic features of Chinese English. Asian Englishes, 11(2), 4-31.

[35] Yan H (2020). A Quantitative Study of Chinese Learners' Identities as Reflected in Their Attitudes Toward English Accents. Journal of Language Studies, 20(1), 151-168.

[36] Ying W, Hui W \& Yuren L (2020). Language ideologies and English in Chinese primary education. Asian Englishes, 22(2), $179-194$.

[37] Yusop J \& Eric M. (2020). Who 'owns English' in our changing world? Exploring the perception of Thai university students in Thailand. Asian Englishes, 22(3), 297-308.

[38] Zakia A. (2021). Development of Fiji English. Journal of World Englishes and Educational Practices (JWEEP), 3(2), 58-66.

[39] Zhang M. (2021). English as a linguistic resource. English Today 144, 37(1), 34-41.

[40] Zhongbao Z. (2013). Diagnosing the English Speaking Ability of College Students in China - Validation of the Diagnostic College English Speaking Test. RELC Journal, 44(3), 341-359. 